\title{
Why Downside Beta Is Better: An Educational Example
}

James T. Chong, California State University, USA

William P. Jennings, California State University, USA

G. Michael Phillips, California State University, USA

\begin{abstract}
An educational example is presented that is an effective teaching illustration to help students understand the difference between traditional CAPM beta and downside (or down-market) beta and why downside beta is a superior measure for use in personal financial planning investment policy statements.
\end{abstract}

Keywords: CAPM; Downside Beta; Investment Policy Statements; Teaching Illustration

\section{INTRODUCTION}

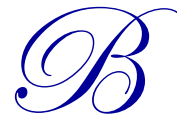

eta is ubiquitous in investment planning as a measure of the relative riskiness of an asset or portfolio compared to the overall market risk. Beta is often used as a limit on acceptable investments in investment policy statements. Beta is provided as a statistic in numerous printed and electronic databases and is widely used to summarize portfolio risk characteristics.

This paper proposes that downside beta - a beta estimated just from those data points of the asset or portfolio return when the benchmark return is negative - is a superior measure. This is because traditional beta includes any observations when the asset or portfolio outperforms the benchmark. If there is any asymmetry in the returns process, this could result in a misstatement of beta and lead to the incorrect exclusion of assets from consideration.

\section{THE BASIC EXAMPLE}

Consider the follow simple example: Suppose you have an investment policy statement in which a client specifies that she only wants assets with beta less than or equal to 1 . That is, she only wants assets that are no riskier than the market portfolio.

Now, suppose that there are two assets to consider. Mutual fund A is identical to the market portfolio and has a beta of 1 regardless of whether the market is rising or falling. Mutual fund B is identical to the market portfolio on days that the market goes down, but goes up twice as much as the benchmark on up-days in the market. Figure 1 shows a comparison of these two investments in returns space, with the market index return as the horizontal axis. Note that P1SIM1 and P1SPX are essentially identical in returns. 
Figure 1: Returns For Two Simulated Series (Y-axis) Against Returns For S\&P Index (X-axis)

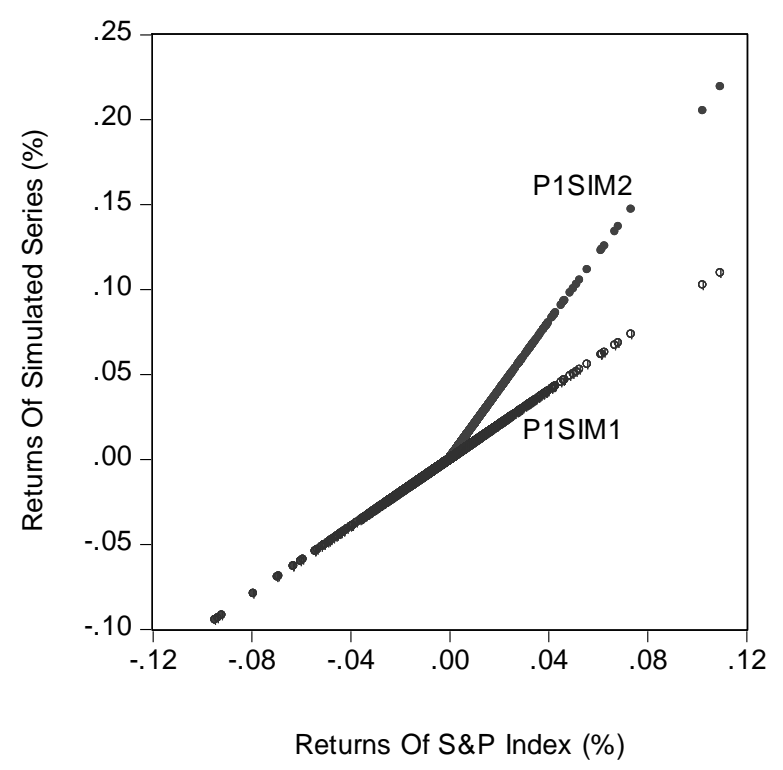

When the two returns series are plotted against each other, the difference between the two simulated portfolios becomes more apparent (Figure 2).

Figure 2: Comparison Of Two Simulated Series (Same Downside Beta, Series 1 With Lower Upside Beta, Series 2 With Higher Upside Beta)

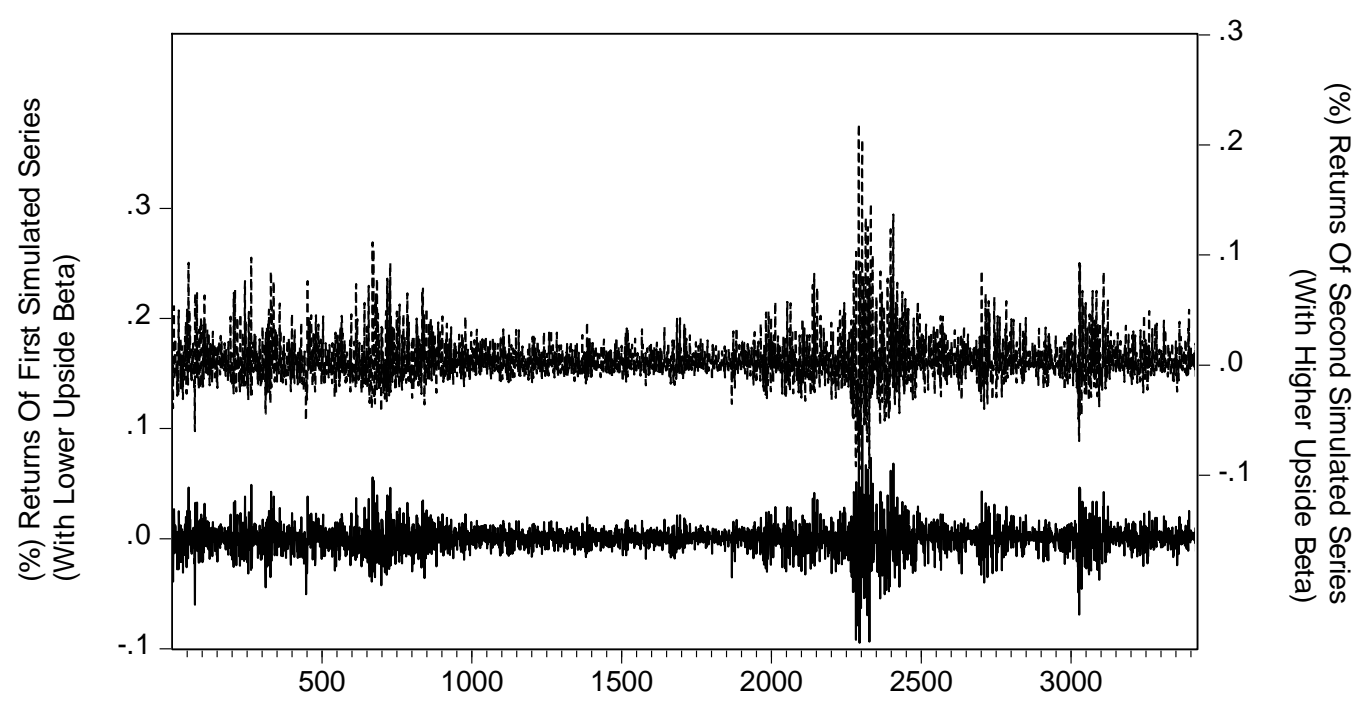

("Daily" Observation Numbers Showing Sequential Simulated Results)

- P1SIM1 ---- P1SIM2 
One can see that the P1SIM2 line, the second simulation, exceeds the first but is never less. (Figure 3).

When converting from returns space into price space, the real difference in these portfolios is apparent

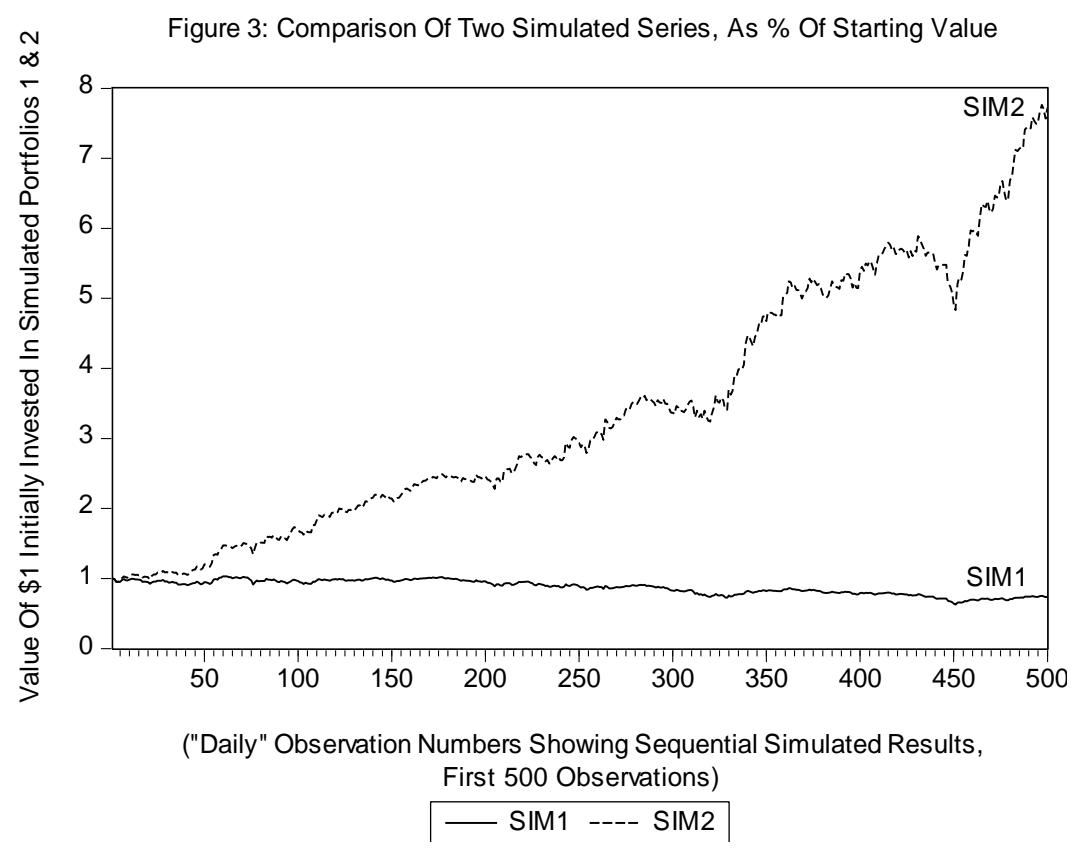

Now, one asks the students which portfolio is preferred: The dashed one (PISIM2) or the solid one (P1SIM1)? Virtually everybody would prefer the dashed-line since the two portfolios have the same downside movement, but the dashed-line portfolio shows substantially greater gain.

Running a basic market model equation against each of the two simulated portfolios verifies that the estimated beta for P1SIM1 is 1 and the estimated beta for P1SIM2 is 1.489.

According to the investment policy statement's guidelines, the dominant portfolio would not be acceptable because the beta exceeds the market.

If instead a downside beta measure was used, finding the beta using just those days when the market return was negative, then both investments would have the same downside beta, 1. At that point, other criteria such as upside beta (1 for P1SIM1 and 2 for P1SIM2) could be used to determine which investment is most appropriate.

\section{CONCLUSION}

Downside beta is not a hard concept, but it is unfamiliar to many financial professionals and students and is seldom discussed in textbooks. For purposes of investment policy statements, it is superior to traditional beta because it does not confuse positive return-profits—with loss.

This simple, yet effective, example quickly illustrates these differences and the problem with an investment policy statement designed to use beta limits.

Additional information on downside beta is available in Chong, Halcoussis, and Phillips (2012), Chong, Pfeiffer, and Phillips (2011), and Chong and Phillips (2011). 


\section{AUTHOR INFORMATION}

James T. Chong, Ph.D., is a Professor and Associate Director of the Center for Financial Planning and Investment at California State University, Northridge. He also serves as a Research Economist at MacroRisk Analytics. He received his Ph.D. in Finance from the ICMA Centre, The University of Reading. E-mail: jchong@csun.edu

William P. Jennings, Ph.D., is Professor of Finance and Emeritus Dean of Business at California State University, Northridge, where he currently serves as Interim Vice President of University Advancement. He received his Ph.D. from the University of California, Los Angeles. E-mail: william.jennings@ csun.edu

G. Michael Phillips, Ph.D., is the Director of the Center for Financial Planning and Investment and a Professor of Finance, Real Estate, and Insurance at California State University, Northridge. He also serves as Chief Scientist for MacroRisk Analytics. He received his Ph.D. from the University of California, San Diego, with specializations in econometrics and applied economics. E-mail: mphillips@csun.edu (Corresponding author)

\section{REFERENCES}

1. Chong, James, Dennis Halcoussis, and G. Michael Phillips. (2012). Misleading Betas: An Educational Example. American Journal of Business Education, 5(5), 617-622.

2. Chong, James, Shawn Pfeiffer, and G. Michael Phillips. (2011). Can Dual Beta Filtering Improve Investor Performance? Journal of Personal Finance, 10(1), 63-86.

3. Chong, James, and G. Michael Phillips. (2011). Beta Measures Market Risk Except When It Doesn't:

Regime-Switching Alpha and Errors in Beta. The Journal of Wealth Management, 14(3), 67-72. 